We presented a case of a patient affected by a giant aneurysm with large airway obstruction and recurrent respiratory failure. He successfully underwent a multistep, noninvasive endobronchialendovascular procedure, and as far as we know, this is the first report of TAA with airways compression similarly approached. After endobronchial placement of a 14-mm covered stent in the left main bronchus and a 13-mm Y-shaped silicon stent in the carina and right main bronchus, the patient underwent endovascular TAA repair. Further steps were carinal stent removal with positioning of a tracheal stent after 15 days and tracheal stent removal on postoperative day 147 .

In conclusion, the endobronchial-endovascular approach ensured successful management of symptoms and effective treatment of TAA, enabling an expeditious postoperative recovery and no recurrence of symptoms.

\section{References}

1. Dake MD, Kato N, Mitchell RS, Semba CP, Razavi MK, Shimono T, et al. Endovascular stent-graft placement for the treatment of acute aortic dissection. N Engl J Med. 1999;340:1546-52.

2. Madden BP, Datta S, Charokopos N. Experience with Ultraflex expandable metallic stents in the management of endobronchial pathology. Ann Thorac Surg. 2002;73:938-44.

3. Demers P, Miller DC, Mitchell RS, Kee ST, Sze D, Razavi MK, et al. Midterm results of endovascular repair of descending thoracic aortic aneurysms with first-generation stent grafts. J Thorac Cardiovasc Surg. 2004;127:664-73.

4. Mitchell RS, Dake MD, Sembra CP, Fogarty TJ, Zarins CK, Liddel RP, et al. Endovascular stent-graft repair of thoracic aortic aneurysms. J Thorac Cardiovasc Surg. 1996;111:1054-62.

5. Miyazawa T, Miyazu Y, Iwamoto Y. Stenting at the flow-limiting segment in tracheobronchial stenosis due to lung cancer. Am J Respir Crit Care Med. 2004;169:1096-102.

\title{
Caseous calcification of the mitral annulus
}

\author{
Hatem Alkadhi, MD, ${ }^{a}$ Sebastian Leschka, MD, ${ }^{a}$ René Prêtre, MD, ${ }^{\mathrm{b}}$ Aurel Perren, MD, ${ }^{\mathrm{c}}$ Borut Marincek, MD, and

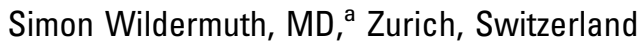

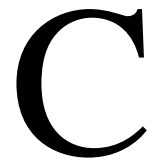

aseous calcification of the mitral annulus is a rare variant of mitral annular calcification that should be included in the differential diagnosis of intracardiac masses. ${ }^{1}$ We present the computed tomography (CT), intraoperative, and histopathologic findings of a 70-year-old woman with mitral stenosis caused by a large caseous calcification located in the posterior mitral annulus.

\section{Clinical Summary}

A 70-year-old woman was admitted with progressive shortness of breath, orthopnea, and several syncopal episodes in the last 6 months. Her history was remarkable for a long-standing hypertonia. A transthoracic echocardiogram revealed an echo-intense

\footnotetext{
From the Institute of Diagnostic Radiology, ${ }^{a}$ Clinic for Cardiovascular Surgery, ${ }^{\mathrm{b}}$ and Department of Pathology, ${ }^{\mathrm{c}}$ University Hospital Zurich, CH8091 Zurich, Switzerland.

The work was supported by the National Center of Competence and Research, Computer Aided and Image Guided Medical Interventions of the Swiss National Science Foundation.

Received for publication Oct 27, 2004; accepted for publication Nov 4, 2004.

Address for reprints: Hatem Alkadhi, MD, Department of Medical Radiology, Institute of Diagnostic Radiology, University Hospital Zurich, Rämistrasse 100, CH-8091 Zurich, Switzerland (E-mail: hatem.alkadhi@usz.ch).

J Thorac Cardiovasc Surg 2005;129:1438-40

$0022-5223 / \$ 30.00$

Copyright $\odot 2005$ by The American Association for Thoracic Surgery

doi:10.1016/j.jtcvs.2004.11.051
}

mass with central echolucencies attached to the posterior mitral annulus causing mitral stenosis. For further characterization of the lesion, a 64-slice multidetector row CT (Sensation 64, Siemens, Germany) with retrospective electrocardiographic triggering after intravenous administration of iodinated contrast material was performed. CT showed an oval $3 \times 3-\mathrm{cm}$ mass located in the posterior mitral annulus with peripheral calcifications and central hyperdensity. Reconstructions during mid-systole showed the broad-based attachment of the lesion to the posterior leaflet; during middiastole, the mass hindered a complete opening of the posterior leaflet, thus leading to mitral stenosis (Figure 1).

At surgery, the nodular, exophytic mass was excised, and a pasty, white material that filled the center of the mass was aspirated (Figure 2). The mitral valve was subsequently reconstructed with ring annuloplasty. Cultures for bacteria, fungi, and acid-fast bacilli did not yield infectious organisms, and histochemical stains showed negative results. Histopathologic examination of the pasty material showed a dense, amorphous, acellular and basophilic substance with scattered calcifications and sparse histiocytes (Figure 3). Inflammatory cells were absent. Thus, the diagnosis of caseous calcification of the mitral annulus was established.

\section{Discussion}

Mitral annular calcification is a degenerative abnormality of the cardiac fibrous skeleton that occurs mainly in elderly individuals. ${ }^{2}$ It usually involves the mid-base of the posterior leaflet but may also involve other segments of the mitral annulus. Caseous calcification is a less-known and rarely described entity representing a variant of mitral annular calcification, which is typically located in the posterior mitral annulus. ${ }^{1}$ It presents as a soft, periannular calcification and is composed of an admixture of calcium, fatty acids, and cholesterol with a "toothpaste-like" texture. The echo- 


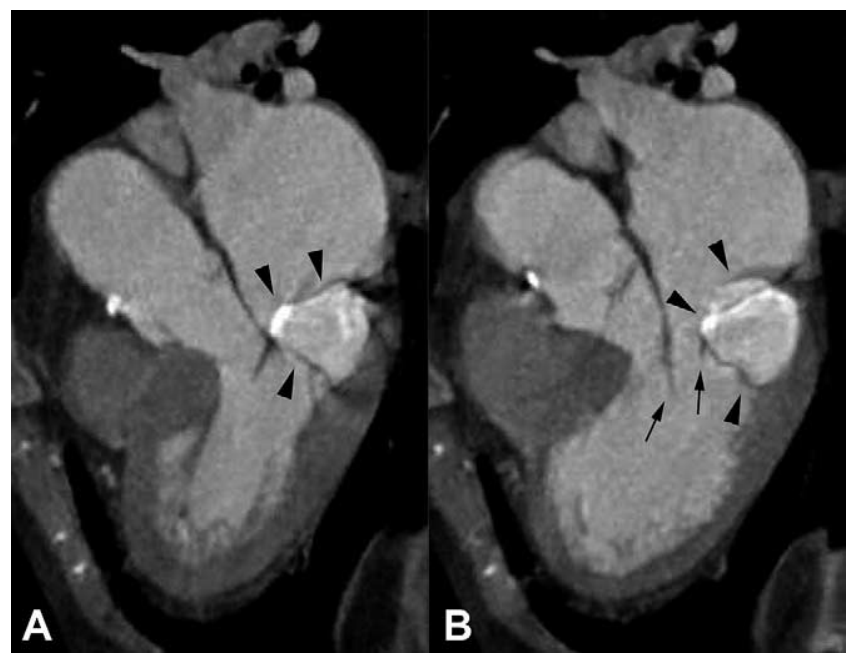

Figure 1. Computed tomography (CT) reconstructions parallel to the long-axis of the left ventricle during mid-systole $(A)$ and mid-diastole (B) demonstrate the centrally hyperdense, peripherally calcified mass (arrowheads) located in the posterior mitral annulus and attached to the posterior leaflet. Complete opening of the valve leaflets during diastole (arrows) is hindered by the attachment of the caseous calcification to the posterior leaflet.

cardiographic prevalence of caseous calcification is $0.6 \%$ in patients with mitral annular calcification and $0.06 \%$ to $0.07 \%$ in large series of patients of all ages. ${ }^{3}$ The prevalence in necropsy series has been reported to be $2.7 \%,{ }^{2}$ however, which indicates that this entity is not yet adequately recognized by most clinicians. ${ }^{1,3}$

In the largest reported series of 18 patients, the echocardiographic finding of caseous calcification in all except 1 patient was incidental and mostly unrelated to symptoms. ${ }^{1}$ Similar to the case in this study, the symptomatic patient had mitral stenosis caused by the mass obstructing the mitral inflow. Baseline clinical characteristics of patients with caseous calcification and mitral annular calcification are comparable; therefore, the diagnosis of caseous calcification cannot be made on the basis of clinical symptoms and findings. ${ }^{1}$ Similarly, autopsy findings such as severe coronary artery disease, aortic atherosclerosis, and a history of hypertension are equally prevalent among patients with both mitral annular calcification and caseous calcification. $^{2}$

Several misdiagnoses of caseous calcification as abscesses and cardiac tumors have been reported. ${ }^{1}$ Therefore, the imaging appearance of this entity deserves further elucidation. As was the case in this patient, caseous calcification is usually detected by transthoracic or transesophageal echocardiography and is characterized as a round or semilunar, echo-dense mass with smooth borders, sometimes encircling a central area of echolucency resembling liquefaction. ${ }^{1,3-5}$ The CT appearance, which has never been demonstrated before, consisted of a well-defined, oval, hyperdense mass with peripheral calcifications in our patient. The

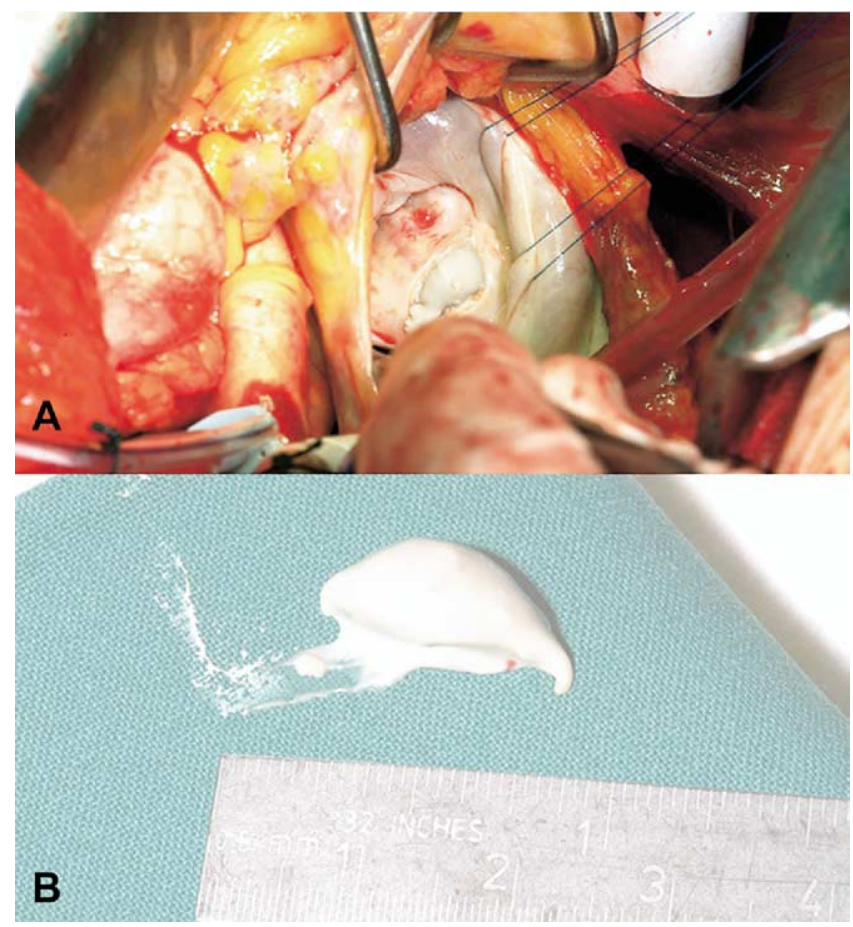

Figure 2. Intraoperative photograph demonstrating the caseous calcification after incision (A). Pasty white material was subsequently aspirated (B).

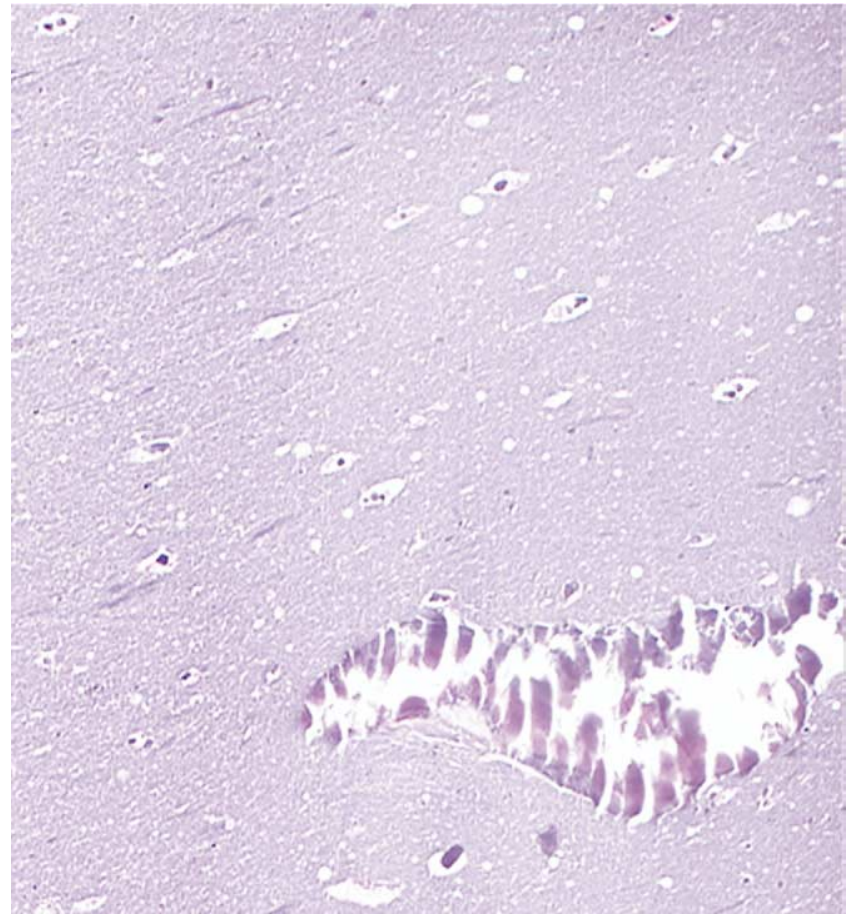

Figure 3. Histologic section of the aspirate shows an amorphous, basophilic substance with scattered calcifications and sparse histiocytes (magnification $\times 200$; hematoxylin-eosin stain). 
central hyperdensity on CT is most likely explained by the pathologic finding of a dense, tenacious substance filling the center of the mass. Distinguishing features between mitral annular abscess and caseous calcification include the lack of larger amounts of calcification in the case of mitral abscesses. ${ }^{4} \mathrm{~A}$ cardiac tumor can be ruled out on CT by the lack of soft-tissue density and absence of contrast enhancement.

In summary, caseous calcification represents a rare, underappreciated variant of mitral annular calcification that should be differentiated from an abscess or tumor. It is likely that the growing clinical use of cardiac CT may increasingly uncover this rare entity.

\section{References}

1. Harpaz D, Auerbach I, Vered Z, Motro M, Tobar A, Rosenblatt S. Caseous calcification of the mitral annulus: a neglected, unrecognized diagnosis. J Am Soc Echocardiogr. 2001;14:825-31.

2. Pomerance A. Pathological and clinical study of calcification of the mitral valve ring. J Clin Pathol. 1970;23:354-61.

3. Novaro GM, Griffin BP, Hammer DF. Caseous calcification of the mitral annulus: an underappreciated variant. Heart. 2004;90:388.

4. Kronzon I, Winer HE, Cohen ML. Sterile, caseous mitral anular abscess. J Am Coll Cardiol. 1983;2:186-90.

5. Teja K, Gibson RS, Nolan SP. Atrial extension of mitral annular calcification mimicking intracardiac tumor. Clin Cardiol. 1987;10: 546-8.

\title{
Giant metastatic myxoid liposarcoma of the mediastinum: A case report
}

\author{
Gabriele Di Giammarco, MD, Michele Di Mauro, MD, Marco Pano, MD, Sergio Cirmeni, MD, Marco Contini, MD, \\ Carlo Di Lorenzo, MD, Antonio Bivona, MD, and Gerardo Liberti, MD, Chieti, Italy
}

$\mathrm{M}$ yxoid liposarcoma is a very uncommon primary neoplasm in the mediastinum, representing $9 \%$ of all primary sarcomas in this area. ${ }^{1,2}$ It develops preferentially in the lower extremities $(75 \%)$ and less frequently in the retroperitoneum. ${ }^{1}$ Myxoid liposarcoma usually metastasizes in the lungs and bone, ${ }^{1}$ and rarely in the mediastinum. ${ }^{3}$ The time interval between the first presentation and the pericardial metastasis ranges from 7 to 25 years. ${ }^{1}$ A case of giant metastatic myxoid liposarcoma in the pericardium causing cardiac tamponade is reported.

\section{Clinical Summary}

A 62-year-old man underwent 3 resections of a primary myxoid liposarcoma of the left thigh in 1983, 1985, and 1989. He was admitted to the hospital with reports of dyspnea for the previous 3 weeks and chest pain of recent onset. The computed tomography (CT) scan performed 6 months previously at a follow-up examination did not show any metastasis. No abnormalities were evident on the electrocardiogram. The chest radiography revealed a widened mediastinum. Echocardiography showed a big mass in the pericardium compressing the right sections of the heart. The CT scan confirmed the presence of a mediastinal mass with dimen-

\footnotetext{
From the Division of Cardiac Surgery, University “G D'Annunzio," ChietiPescara, Chieti, Italy.

Received for publication Dec 10, 2004; accepted for publication Jan 10, 2005.

Address for reprints: Gabriele Di Giammarco, MD, Chief of Division of Cardiac Surgery, University "G D'Annunzio," S Camillo Hospital, v Forlanini 50, 66100 Chieti, Italy (E-mail: gabriele.digiammarco1@tin.it).

J Thorac Cardiovasc Surg 2005;129:1440-2

$0022-5223 / \$ 30.00$

Copyright $\odot 2005$ by The American Association for Thoracic Surgery

doi:10.1016/j.jtcvs.2005.01.010
}

sions of $23.5 \times 18.0 \times 15.0 \mathrm{~cm}$ (Figure 1). On the same day, the patient underwent surgical resection.

After the chest was opened through a median sternotomy, the pericardium appeared very tense and consistently hard. The pericardium was incised, starting from a cranial point where the surface was less tense. Soon after, we noticed that the inferior surface of the heart was displaced cranially to the mid-transverse line of the anterior mediastinum. The majority of the pericardium was occupied by the neoplasm, and the heart appeared undersized. The tumor was free from adhesions throughout the entire circumference except for a small area infiltrating the inferior wall of the right ventricle close to the apex. Cardiopulmonary bypass was established with both venae cavae cannulated. Myocardial protection was achieved by intermittent antegrade warm blood cardioplegia. The mass was easily dissected from the diaphragm. The infiltrating area was extensively resected over normal muscle, and the ventriculotomy was repaired with an equine pericardial patch $(8.0 \times 6.0 \mathrm{~cm})($ Edwards LifeSciences LLC, Irvine, Calif $)$ sutured with a running 4-0 Prolene suture (Ethicon, Somerville, NJ).

The patient had an uneventful postoperative recovery and was discharged on the fifth postoperative day. The first CT did not show any recurrence of the tumor.

The resected mass measured $21.0 \times 17.0 \times 15.0 \mathrm{~cm}$ and weighed $2430 \mathrm{~g}$. It was yellowish and mainly encapsulated except for the infiltrating area. The cut surface revealed myxoid and necrotic areas. Microscopy showed prevalent myxoid stroma containing lipoblasts and myocytes in the infiltrating area (Figure 2). It was labeled grade I, with the percentage of round cells less than $10 \% .^{1}$

\section{Discussion}

Wong and colleagues ${ }^{4}$ reported a case of a 54-year-old patient with a previously resected liposarcoma of the left pectoralis muscle who underwent operation for a metastatic tumor located in the anterior mediastinum and measuring $18 \times 14 \mathrm{~cm}$. They stated that the 